\title{
Sex and depression in the National Comorbidity Survey I: Lifetime prevalence, chronicity and recurrence
}

\author{
Ronald C. Kessler ${ }^{\text {a.b,* }}$, Katherine A. McGonagle ${ }^{a}$, Marvin Swartz ${ }^{c}$, Dan G. Blazer ${ }^{c}$ \\ and Christopher B. Nelson ${ }^{\text {a }}$ \\ ${ }^{a}$ Institute for Social Research Box 1248, and ${ }^{b}$ Department of Sociology, Box 1248, University of Michigan, Ann Arbor, MI, USA, and \\ ${ }^{c}$ Department of Psychiatry, Duke University Medical Center, Durham, NC, USA
}

\section{Summary}

Basic epidemiologic prevalence data are presented on sex differences in DSM-III-R major depressive episodes (MDE). The data come from the National Comorbidity Survey (NCS), the first survey in the U.S. to administer a structured psychiatric interview to a nationally representative sample of the general population. Consistent with previous research, women are approximately 1.7 times as likely as men to report a lifetime history of MDE. Age of onset analysis shows that this sex difference begins in early adolescence and persists through the mid-50s. Women also have a much higher rate of 12-month depression than men. However, women with a history of depression do not differ from men with a history of depression in either the probability of being chronically depressed in the past year or in the probability of having an acute recurrence in the past year. This means that the higher prevalence of 12-month depression among women than men is largely due to women having a higher risk of first onset. The implications of these results for future research are discussed in a closing section of the paper.

Key words: Depression; Sex; Lifetime prevalence; Chronicity; Recurrence

One of the most widely documented findings in psychiatric epidemiology is that women have higher rates of major depression than men. This has been found consistently in community epidemiologic studies throughout the world using a variety of diagnostic schemes and interview meth-

\footnotetext{
* Corresponding author.

Presented at the NIMH Workshop, 'Towards a New Psychobiology of Depression in Women,' September 18, 1992.
}

ods (Bebbington et al., 1981; Bland et al., 1988a,b; Canino et al., 1987; Cheng, 1989; Hwu et al., 1989; Lee et al., 1987; Weissman and Myers, 1978; Wells et al., 1989; Wittchen et al., 1992; for reviews see Bebbington, 1988; Nolen-Hoeksema, 1987; Weissman and Klerman, 1977, 1985, 1992; Weissman et al., 1984). The prevalence of depression among women has typically been between one and a half to three times that found among men. The purpose of this paper is to present new epidemiologic data on this sex difference in de- 
pression from the National Comorbidity Survey (NCS), a recently completed survey that included general population data on the prevalence of DSM-III-R major depression.

\section{Methods}

\section{Sample}

The NCS is a Congressionally mandated survey of psychiatric disorders in the U.S. designed to produce data on the prevalence, risk factors, and consequences of psychiatric morbidity and comorbidity. The NCS is the first nationally representative general population survey of the U.S. to administer a structured psychiatric interview and the first large-scale psychiatric epidemiologic survey in the U.S. to use DSM-III-R (American Psychiatric Association, 1987) diagnostic criteria. The 8098 respondents who participated in the NCS were selected from 1205 block-level segments in 176 counties throughout the country based on a stratified, multi-stage area probability sampling scheme which included both persons in the noninstitutionalized civilian population and a supplemental sample of students living in campus group housing. The age range of respondents was 15-54. The survey was administered by the staff of the Survey Research Center at the University of Michigan. The field period was between September 14, 1990 and February 6, 1992. The

TABLE 1

Characteristics of NCS respondents compared to the U.S. population *

\begin{tabular}{|c|c|c|c|c|}
\hline & & $\begin{array}{l}\text { US } \\
\text { population }\end{array}$ & $\begin{array}{l}\text { NCS } \\
\text { weighted }\end{array}$ & $\begin{array}{l}\text { NCS } \\
\text { unweighted }\end{array}$ \\
\hline$\overline{\operatorname{Sex}}$ & $\begin{array}{l}\text { Male } \\
\text { Female }\end{array}$ & $\begin{array}{l}49.1 \% \\
50.9\end{array}$ & $\begin{array}{l}49.5 \% \\
50.5\end{array}$ & $\begin{array}{l}47.5 \% \\
52.5\end{array}$ \\
\hline Race & $\begin{array}{l}\text { White } \\
\text { Black } \\
\text { Hispanic } \\
\text { Other }\end{array}$ & $\begin{array}{l}75.0 \% \\
11.9 \\
8.6 \\
4.5\end{array}$ & $\begin{array}{l}75.3 \% \\
11.5 \\
9.7 \\
3.5\end{array}$ & $\begin{array}{l}75.1 \% \\
12.5 \\
9.1 \\
3.3\end{array}$ \\
\hline Education & $\begin{array}{l}0-11 \\
12 \\
13-15 \\
>=16\end{array}$ & $\begin{array}{l}22.5 \% \\
36.8 \\
21.2 \\
19.5\end{array}$ & $\begin{array}{l}22.3 \% \\
37.4 \\
21.7 \\
18.6\end{array}$ & $\begin{array}{l}18.2 \% \\
33.1 \\
26.3 \\
22.4\end{array}$ \\
\hline Marital status & $\begin{array}{l}\text { Married } \\
\text { Sep/Wid/Div } \\
\text { Never Married }\end{array}$ & $\begin{array}{l}59.8 \% \\
10.1 \\
30.1\end{array}$ & $\begin{array}{l}62.9 \% \\
10.0 \\
27.1\end{array}$ & $\begin{array}{l}54.4 \% \\
15.5 \\
30.1\end{array}$ \\
\hline Region & $\begin{array}{l}\text { North East } \\
\text { Mid West } \\
\text { South } \\
\text { West }\end{array}$ & $\begin{array}{l}20.0 \% \\
24.6 \\
33.7 \\
21.7\end{array}$ & $\begin{array}{l}20.2 \% \\
23.8 \\
36.4 \\
19.6\end{array}$ & $\begin{array}{l}19.2 \% \\
25.6 \\
35.6 \\
19.6\end{array}$ \\
\hline Age & $\begin{array}{l}15-24 \\
25-34 \\
35-44 \\
45-54\end{array}$ & $\begin{array}{l}25.5 \% \\
30.8 \\
25.9 \\
17.8\end{array}$ & $\begin{array}{l}24.7 \% \\
30.1 \\
27.1 \\
18.1\end{array}$ & $\begin{array}{l}21.8 \% \\
32.4 \\
27.7 \\
18.1\end{array}$ \\
\hline Urbanicity & $\begin{array}{l}\text { MSAs }>=250 \\
\text { MSAs }<250 \\
\text { Not MSA }\end{array}$ & $\begin{array}{l}71.2 \% \\
8.1 \\
20.7\end{array}$ & $\begin{array}{c}67.8 \% \\
7.5 \\
24.7\end{array}$ & $\begin{array}{l}68.9 \% \\
6.5 \\
24.6\end{array}$ \\
\hline Total number & & $(65244)$ & $(8098)$ & $(8098)$ \\
\hline
\end{tabular}

* U.S. Population characteristics based on results from the 1989 U.S. National Health Interview Survey. 
response rate was $82.4 \%$. More details about the design of the NCS are presented elsewhere (Kessler et al., submitted).

A special design feature of the NCS is that a nonresponse survey was carried out in which a sample of initial nonrespondents were offered a financial incentive to complete a short-form of the diagnostic interview. Significantly higher rates of both lifetime and current depression were found among these initial nonrespondents than among respondents in the main survey. This result is consistent with previous research which has shown that persons with a history of psychiatric disorder are under-represented in both cross-sectional surveys (Allgulander, 1989) and reinterview surveys (Eaton et al., 1992) of the general population. The survey data were weighted to compensate for this nonresponse. The data were also weighted to adjust for variation in probabilities of selection within households and were post-stratified to approximate the national population distributions of the crossclassification of age, sex, race/ethnicity, marital status, education, living arrangements, region, and urbanicity as defined by the 1989 U.S. National Hcalth Intcrvicw Survey (U.S. Department of Health and Human Services, 1992). A comparison of weighted and unweighted NCS distributions on demographic variables is presented in Table 1.

\section{Diagnostic assessment}

DSM-III-R diagnoses of major depressive episode (MDE) are based on a modified version of the Composite International Diagnostic Interview (CIDI; World Health Organization, 1990a). The CIDI is a structured diagnostic interview based on the Diagnostic Interview Schedule (DIS; Robins et al., 1981) that was developed collaboratively by WHO/ADAMHA (Robins et al., 1988) to foster epidemiologic and cross-cultural comparative research by producing diagnoses according to the definitions and criteria of both DSMIII-R (American Psychiatric Association, 1987) and the Diagnostic Criteria for Research of the ICD-10 (World Health Organization, 1990b). WHO field trials of the CIDI have documented good inter-rater reliability (Cottler et al., 1991; Wittchen et al., 1991) and test-retest reliability
(Semler et al., 1987; Wacker et al., 1990) as well as good agreement with clinical diagnoses (Farmer et al., 1987, 1991; Janca et al., 1992; Leitmeyer, 1990; Semler et al., 1987; Semler, 1989; Spengler and Wittchen, 1989; Wittchen et al., 1989).

Most general population studies of MDE over the past decade have been based on the DIS, so it is important to comment on differences in the questions used to diagnose MDE in the version of the CIDI used in the NCS and the DIS. While the two are identical in most respects, there is a critical difference in the depth of probing for lifetime recall of episodes. NCS pilot tests showed that there are two under-reporting problems with the standard DIS/CIDI method of interviewing. First, some respondents under-report stem questions for MDE and other disorders once they recognize that positive responses will lead to more detailed questions. Second, most respondents fail to appreciate the complexity of answering stem questions which require them to review lifetime occurrence of episodes. In order to address these problems, we turned to the survey methods literature on recall failure and discovered that survey methodologists have developed a variety of procedures to help improve retrospective recall (Bradburn et al., 1979; Cannell et al., 1977;1979; Henson et al., 1976; Sudman and Bradburn, 1974; Turner and Martin, 1984). Drawing on this extensive research, we modified the standard DIS/ CIDI question structure to include the stem questions for MDE and a number of other disorders in a new Life Review Section. This Life Review Section was designed to facilitate active memory search for lifetime episodes. In addition to the general motivation probes, the Life Review Section included three separate stem questions for MDE rather than the one stem question used in the DIS. These three inquired about episodes of feeling 'sad, blue or depressed', feeling 'down in the dumps or gloomy', and 'losing interest in most things like work, hobbies, or things you usually liked to do for fun'. In addition to its use in aiding recall, the Life Review Section was administered prior to probing any positive stem responses in an effort to avoid conscious nondisclosure of stem questions once respondents recognized that positive stem responses lead to further questioning. 
That these refinements did not lead to over-reporting is indicated by the fact that blind clinical reinterviews in a random subsample of NCS respondents using the SCID as the validation standard yielded a positive predictive value of $0.70( \pm 0.10)$ and a negative predictive value of $0.96( \pm 0.06)$. These results compare favorably with those obtained in previous general population validation studies of MDE in the DIS (Anthony et al., 1985; Helzer et al., 1985; Robins et al., 1981). There have been no previous general population validation studies of MDE in the CIDI.

\section{Analysis procedures}

As a result of the complex sample design and weighting of the NCS data, estimates of standard errors based on the usual assumption of equalprobability simple random sampling are biased. More complex analysis methods are needed to obtain appropriate standard errors. Estimates of standard errors of proportions were obtained using the Taylor series linearization method (Woodruff and Causey, 1976). The PSRATIO program in OSIRIS (University of Michigan, 1981) was used to make these calculations. Estimates of standard errors of logistic regression coefficients (Hosmer and Lemeshow, 1989) and discrete-time hazard coefficients (Allison, 1984) were obtained using the method of Balanced Repeated Replication (BRR; Kish and Frankel, 1970; Koch and Lemeshow, 1972). This procedure began by generating 44 balanced subsamples of the survey data. The LOGISTIC program in
SAS (SAS Institute, 1988) was used to make individual calculations for each of these 44 replicate subsamples. A SAS BRR macro was then used to compute estimates of the standard errors from the distribution of the coefficients in the 44 replicates. These estimates take into consideration the stratified multi-stage and weighted features of the design without the linearization constraint required in the Taylor series method. As this constraint is not problematic in the estimation of proportions (Kalton, 1977; Lepkowski et al., 1988), we used the less computationally intensive Taylor series method for estimating the standard errors of proportions.

\section{Results}

\section{Sex differences in number of diagnostic criteria}

The results in Table 2 show that nearly $46 \%$ of men and $58 \%$ of women in the NCS reported the lifetime occurrence of at least one period lasting 2 weeks or more when they had either persistent depressed mood or markedly diminished interest in most of their normal activities. If endorsement of these stem questions was taken as the only requirement for an episode of depression, the female: male risk ratio would be 1.26 . The risk ratio consistently increases as we increase the required number of additional DSM-III-R Criterion A symptoms. (The B criteria were also used in developing these symptom counts, which means that we excluded symptoms due to organic causes or to normal grief. The C and D hierarchy criteria were ignored.) The risk ratio is 1.43 when one

TABLE 2

Sex ratio of lifetime diagnosis by varying diagnostic criteria

\begin{tabular}{lllll}
\hline \multirow{2}{*}{$\begin{array}{l}\text { Diagnostic } \\
\text { criteria }\end{array}$} & \multicolumn{4}{l}{ Percentage meeting MDE lifetime diagnosis } \\
\cline { 2 - 4 } & Male & Female & Female/Male & Total \\
\hline Stem & 45.70 & 57.60 & 1.26 & 51.70 \\
Stem plus 1 or more symptoms & 25.20 & 35.90 & 1.43 & 30.60 \\
Stem plus 2 or more symptoms & 20.90 & 32.00 & 1.53 & 26.50 \\
Stem plus 3 or more symptoms & 16.60 & 26.90 & 1.62 & 21.80 \\
Stem plus 4 or more symptoms & 12.70 & 21.30 & 1.68 & 17.10 \\
SterI plus 5 or more symptoms & 8.50 & 16.60 & 1.95 & 12.60 \\
Stem plus 6 or more symptoms & 5.70 & 11.00 & 1.93 & 8.40 \\
Stem plus 7 or more symptoms & 3.30 & 6.10 & 1.85 & 4.80 \\
Stem plus all 8 symptoms & 1.20 & 3.00 & 2.50 & 2.10 \\
\hline
\end{tabular}


TABLE 3

Rates of lifetime, 12-month, and 12-month/lifetime MDE by sex and age

\begin{tabular}{|c|c|c|c|c|c|c|c|}
\hline \multirow[t]{3}{*}{$\overline{\operatorname{Sex}}$} & \multirow[t]{3}{*}{ Age } & \multicolumn{2}{|c|}{ Lifetime } & \multicolumn{2}{|c|}{ 12-month } & \multirow{2}{*}{\multicolumn{2}{|c|}{$\begin{array}{l}\text { 12-month/ } \\
\text { lifetime }\end{array}$}} \\
\hline & & \multirow[t]{2}{*}{$\%$} & \multirow[t]{2}{*}{$\mathrm{SF}$} & \multirow[t]{2}{*}{$\%$} & \multirow{2}{*}{ SF: } & & \\
\hline & & & & & & $\%$ & $\mathrm{SE}$ \\
\hline \multirow[t]{5}{*}{ Males } & $15-24$ & 11.0 & 1.8 & 9.5 & 1.7 & 86.4 & 3.5 \\
\hline & $25-34$ & 13.1 & 1.3 & 7.9 & 1.2 & 60.6 & 5.0 \\
\hline & $35-44$ & 14.7 & 1.6 & 8.1 & 1.4 & 55.4 & 4.9 \\
\hline & $45+$ & 11.8 & 1.9 & 4.0 & 1.0 & 33.6 & 7.2 \\
\hline & Total & 12.7 & 0.9 & 7.7 & 0.8 & 60.1 & 3.1 \\
\hline \multirow[t]{5}{*}{ Females } & $15-24$ & 20.8 & 1.9 & 16.3 & 1.9 & 78.4 & 3.8 \\
\hline & $25-34$ & 19.4 & 1.3 & 11.6 & 1.3 & 59.6 & 4.6 \\
\hline & $35-44$ & 23.8 & 1.9 & 12.7 & 1.5 & 53.4 & 3.5 \\
\hline & $45+$ & 21.8 & 2.3 & 11.0 & 1.6 & 50.6 & 5.2 \\
\hline & Total & 21.3 & 0.9 & 12.9 & 0.8 & 60.5 & 1.9 \\
\hline \multirow[t]{5}{*}{ Total } & $15-24$ & 15.7 & 1.3 & 12.8 & 1.4 & 81.3 & 3.1 \\
\hline & $25-34$ & 16.5 & 0.9 & 9.9 & 0.9 & 60.0 & 3.6 \\
\hline & $35-44$ & 19.2 & 1.4 & 10.4 & 1.1 & 54.2 & 2.9 \\
\hline & $45+$ & 16.7 & 1.5 & 7.4 & 1.1 & 44.5 & 4.9 \\
\hline & Total & 17.1 & 0.7 & 10.3 & 0.6 & 60.3 & 1.8 \\
\hline
\end{tabular}

or more symptoms are required, 1.68 when four or more are required as in DSM-III-R, and 2.50 when all eight are required. This pattern is very similar to the pattern reported by Young et al. (1990) in their analysis of data from the nonpatient relatives of depressed probands in the Collaborative Study of the Psychobiology of Depression. These results show that it is not merely the absence of depressed mood or diminished interest that differentiates men from women but lower rates of other symptoms clustering with these core symptoms of depression.

Sex and age differences in the prevalence of $M D E$

Table 3 shows the lifetime and 12-month prevalence estimates for MDE as defined by DSM-III-R along with the ratio of 12 -month prevalence to lifetime prevalence. Results are shown for the total sample as well as for subsamples defined by age and sex. The overall prevalence estimates - $17.1 \%$ lifetime and $10.3 \% 12$ month - are considerably higher than those reported for the same age groups in the Epidemiologic Catchment Area (ECA) Study (Weissman et al., 1991) and other recent epidemiologic studies based on the ECA methodology (Bland et al., 1988a,b; Canino et al., 1987; Chen et al., 1993; Hwu et al., 1989; Wells et al., 1989). In comparison, the NCS prevalence estimates are quite similar to those found in epidemiologic studies based on clinical interviews (Boyd and Weissman, 1981; Kendler et al., 1992; Weissman et al,, 1978). The overall NCS lifetime prevalence estimate of $17.1 \%$ is also similar to the estimate obtained in a recent reanalysis of the ECA which attempted to correct for recall failure by combining wave one and wave two lifetime reports (Regier et al., 1991).

The age trends shown in Table 3 are consistent with results from the ECA (Weissman et al., 1991) in showing that the lifetime prevalence of MDE increases with age among respondents younger than 45 and decreases among older respondents. The results in Table 3 show that this is true for both men and women. The ECA investigators interpreted this as evidence of a cohort effect. Differential mortality, age-related selection bias, cohort differences in willingness to report symptoms, and recall failure related to recency of symptoms are other explanations that are also consistent with this pattern (Simon and VonKorff, 1992). As one would expect for an episodic early-onset disorder like depression, the ratio of 12-month to lifetime prevalence decreases with age from a high of $81 \%$ in the $15-24$ year cohort to a low of $44 \%$ in the $45-54$ year cohort. This is opposite the pattern found in the ECA study, where the ratio of 12 -month prevalence to lifetime prevalence increased with age (Weissman et al., 1991). This means that compared to the ECA, the NCS finds a higher proportion of oldest respondents who report a prior history but no recent episode of depression. This finding is consistent with the likelihood that the NCS Life Review Section succeeded in stimulating more accurate recall of lifetime depression.

The results concerning sex differences in Table 3 are consistent with earlier epidemiologic studies in showing that women have higher lifetime rates of MDE than men. The lifetime female:male relative risk is $1.68(21.3 / 12.7)$ in the total sample. This is lower than the roughly $2.4(8.7 / 3.6)$ lifetime female:male relative risk in the ECA study (Weissman et al., 1991) but virtually identical to the $1.67(35.2 / 21.1)$ lifetime female: male relative risk for first-degree relatives of depressed 


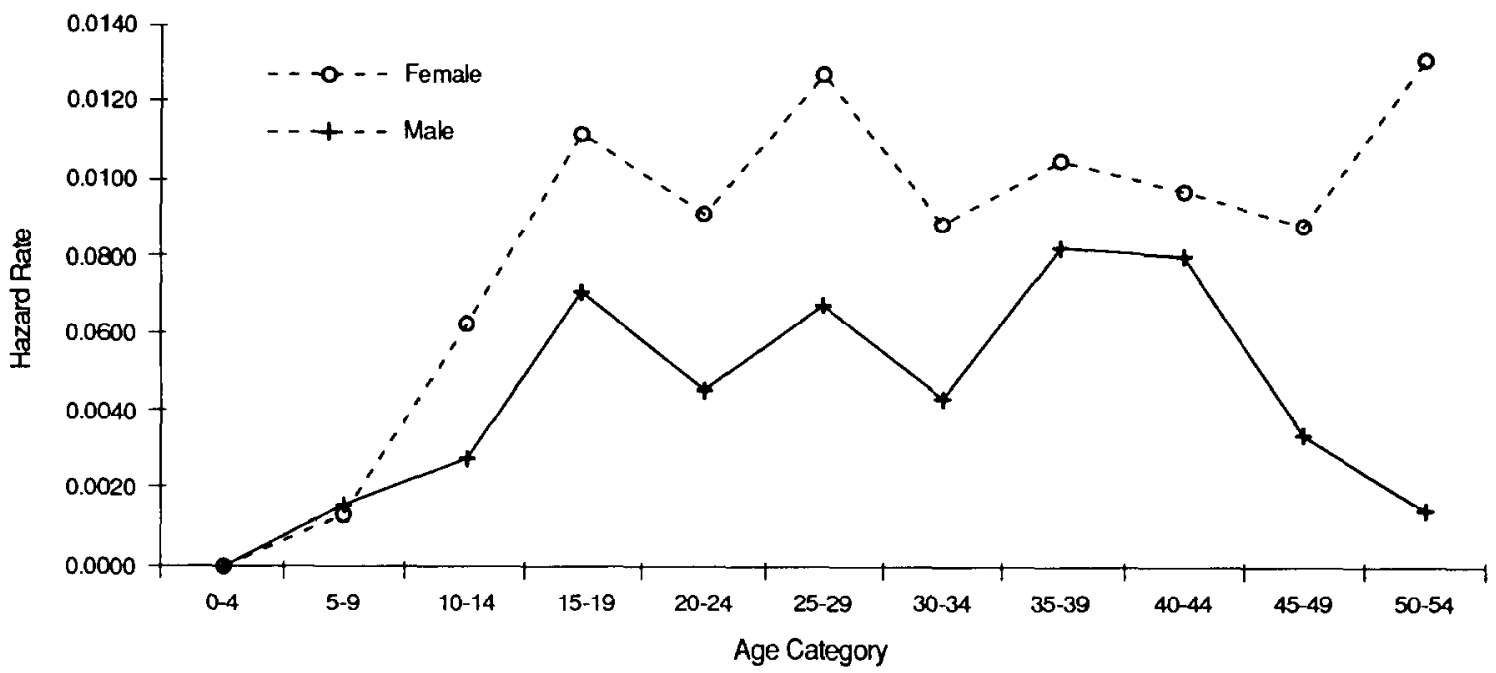

Fig. 1. MDE hazard rates by age and sex.

probands in the Collaborative Study of the Psychobiology of Depression (Young et al., 1990). The NCS 12-month female: male relative risk $1.68(12.9 / 7.7)$ - is identical to the lifetime relative risk. This means that the ratio of 12 -month prevalence to lifetime prevalence, which can be interpreted as a rough measure of chronicity, is virtually identical for men $(60.1 \%)$ and women $(60.5 \%)$, a finding which we explore in detail below.

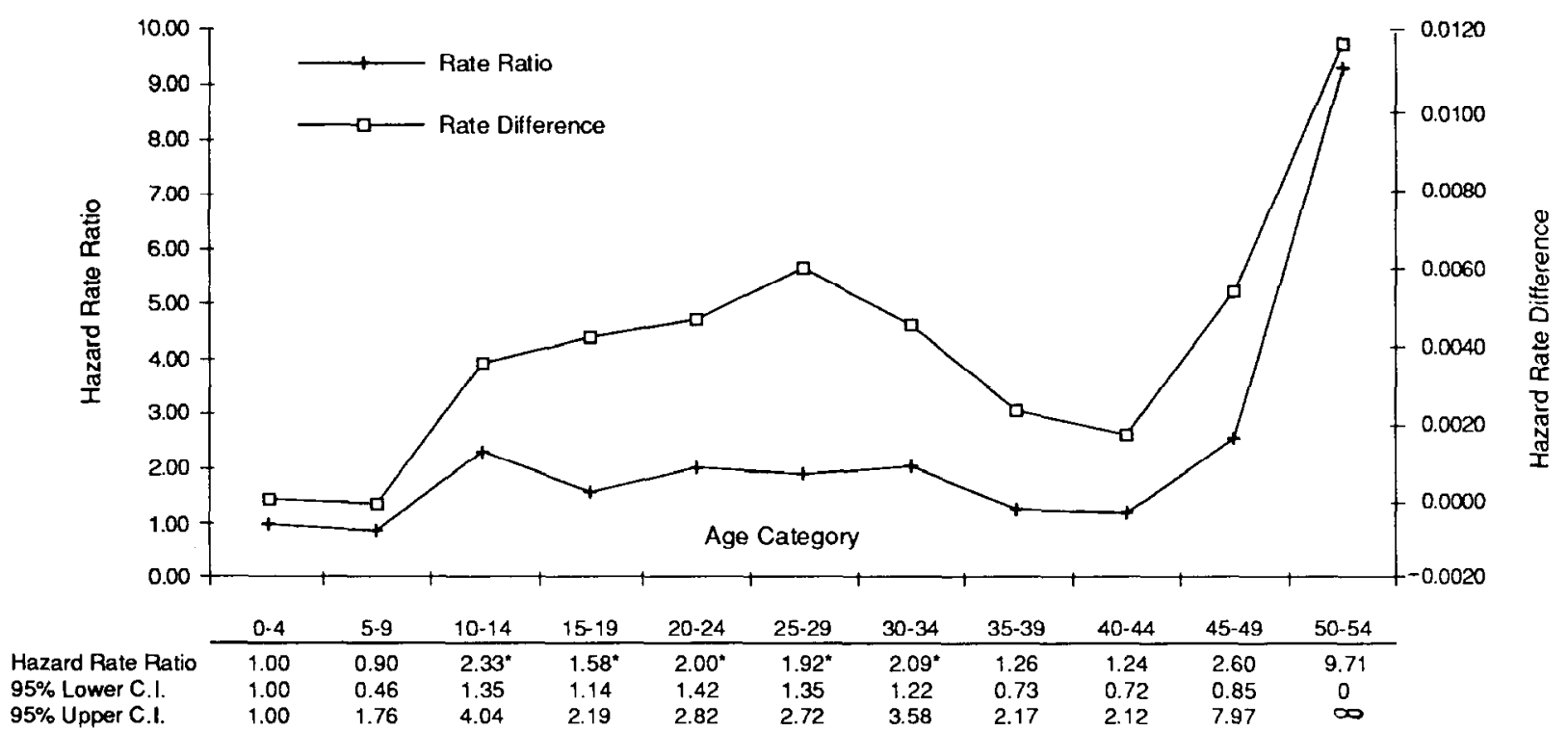

Fig. 2. MDE hazard rate ratios (female: male) and rate differences (female-male). 
Sex differences in age of onset

Consistent with the findings of Weissman and her associates (this issue), we find that there is no significant sex difference in average age of onset of MDE in the NCS. The mean age of onset (standard error) is $24.04(0.67)$ for men and 23.53 $(0.44)$ for women $(t=0.6$, ns). The results in Fig. 1 provide more detailed information about age of onset distributions separately for men and women. The female : male hazard rate ratios and femalemale rate differences are shown in Fig. 2. Women have a higher hazard than men beginning at age 10 and continuing through the mid-50s. The sharp divergence of the trends in the age range 50-54 is based on a very small sample size and is not reliable. The rate ratio does not differ significantly with age $(t=1.2$, ns), although the rate difference does differ significantly with age $(t=$ 2.5, $P<0.05$ ).

These results are generally consistent with the age of onset data in the ECA study (Burke et al., 1990) as well as with a 1-year prospective investigation of first onsets in the two-wave ECA panel sample (Sargeant et al., 1990). One noteworthy difference between the NCS and ECA results, though, is that the sex difference in cumulative onset risk appears 5 years earlier in the NCS - at age 10 in the NCS compared to age 15 in the ECA. This is important because of wide speculation in the literature that the sex difference in depression is triggered by puberty (see NolenHoeksema, 1987, for a review). The beginning of the sex difference by age 10 is more consistent with this speculation than the ECA finding that the sex difference begins at age 15 .

\section{Sex differences in chronicity and recurrence}

The results reported in the last subsection show clearly that women are more likely than men to become depressed. The next question is whether women remain depressed longer than men once onset has occurred. This has been a relatively neglected question in the epidemiologic literature on sex and depression even though sex role theories strongly imply that chronicity should be greater for women than men (scc reviews in Gilbert, 1992; Gotlib and Hammen, 1992; Hammen, 1982; Nolen-Hoeksema, 1987). To the extent that the issue has been studied, the available evidence suggests that women may have more chronic depression than men (Amenson and Lewinsohn, 1981; Aneshensel, 1985; Ernst and Angst, 1992; Merikangas et al., in press). However, the results in Table 3 show that the ratio of 12-month prevalence to lifetime prevalence - a rough measure of illness course - is virtually identical for men $(0.601)$ and women $(0.605)$ in the NCS. Very similar results were found in the ECA study (0.611 ratio for men and 0.515 ratio for women). These results imply that there is no sex difference in the overall course of depression.

At least three separate processes contribute to the size of these ratios: the probability of a first episode becoming chronic, the probability of episode recurrence among people who are not chronically depressed, and speed of episode recovery among people with recurrent episodes. We are able to study the first two of these three processes with the NCS data. To do this, chronic depression was defined as either a single lifetime episode that was still active at the time of interview or current depression among persons with a history of multiple episodes that had never been separated by several months or more of normal functioning. Recurrent depression was defined as an acute onset of a new episode of depression in the 12-month period prior to the NCS interview among the subsample of respondents with a lifetime history who were not chronically depressed.

Female : male odds-ratios (OR) for chronic depression and 12-month acute recurrent depression are reported in Table 4 . The overall OR for chronic depression is 0.81 and the overall $\mathrm{OR}$ for recurrent depression is 1.06 . Neither OR is significant at the 0.05 level, suggesting that despite their greater risk of first onset, women do not have a higher risk than men of either chronic depression or recurrent depression. It is noteworthy that the two largest ORs in this part of the table are for acute recurrence in the age range 45-49 and 50-54. (This can also be seen in a comparison of the ratio of 12 -month prevalence to lifetime prevalence for men and women ages 45 and older in Table 3.) Although not significant statistically because of a small sample size, these elevated ORs are consistent with the results of a 1-year prospective study of the outcome of time 1 major depression in the ECA panel sample 
TABLE 4

Sex difference in chronicity and recurrence of MDE

\begin{tabular}{llllll}
\hline$\Lambda$ ge & \multicolumn{2}{l}{ Chronicity } & & \multicolumn{2}{l}{ Acutc Rccurrence } \\
\cline { 2 - 3 } \cline { 5 - 6 } & OR & $(95 \% \mathrm{CI})$ & & OR & $(95 \% \mathrm{CI})$ \\
\hline $15-19$ & 1.06 & $(0.23,4.90)$ & & 0.83 & $* *$ \\
$20-24$ & 1.14 & $(0.22,5.85)$ & & 0.31 & $(0.09,1.07)$ \\
$25-29$ & 1.04 & $(0.22,4.89)$ & & 0.80 & $(0.25,2.52)$ \\
$30-34$ & 0.72 & $(0.30,1.71)$ & & 1.36 & $(0.59,3.11)$ \\
$35-39$ & 0.71 & $(0.18,2.76)$ & & 2.20 & $(0.69,6.94)$ \\
$40-44$ & 0.51 & $(0.07,3.52)$ & & 0.46 & $(0.19,1.09)$ \\
$45-49$ & 1.09 & $* *$ & & 5.10 & $* *$ \\
$50-54$ & 0.60 & $(0.10,3.49)$ & 35.88 & $* *$ \\
Total & 0.81 & $(0.53,1.25)$ & 1.06 & $(0.71,1.60)$ \\
\hline
\end{tabular}

* Effect of female.

** Low precision.

(Sargeant et al., 1990) which found that older women have a poorer outcome for time 1 depression. (The ECA study did not collect data which would allow chronic and recurrent depression to be distinguished.)

\section{Discussion}

We began by documenting that lifetime rates of MDE are much higher in the NCS than in the ECA or other recent epidemiologic surveys based on the ECA methodology. We suspect that this is due to the joint effects of increasing rates of depression in the more recent cohorts represented in the NCS sample and to two NCS data collection innovations: the nonrespondent survey, which allowed us to correct prevalence estimates for the lower interview completion rate among people with a history of depression, and the Life Review Section, which helped stimulate active memory search for recall of lifetime disorders.

The female : male relative risk of depression in the NCS is 1.7. This is a good deal lower than the relative risk in the ECA, possibly due to the fact that our Life Review Section was more successful in reducing the level of recall failure among men than women. This interpretation is consistent with evidence that men are more likely than women to forget past episodes of depression (Ernst and Angst, 1992). However, we consider it very unlikely that the remaining 1.7 female : male relative risk is due to recall bias. This conclusion is based on the results reported in Table 2, where we saw that women are not much more likely than men to recall the lifetime occurrence of a 2-week episode of dysphoria. Instead, the higher prevalence of lifetime MDE among women is largely due to the fact that women are more likely than men to report symptoms that occurred during their worst 2-week episode which meet diagnostic criteria for MDE. A higher level of recall failure among men than women is unlikely to explain this pattern. Nor is this pattern consistent with the possibility that men are less willing to admit depression than women, as the results show that men do not so much report lower rates of depressive episodes as associated symptoms. Based on these results, we believe that the observed sex difference in lifetime prevalence is genuine rather than due to some methodological artifact.

Age of onset analysis shows that female respondents report an elevated risk of first onset compared to males as early as age 10 . Consistent with other research showing that the sex difference in depression is most pronounced among early adolescents (Brooks-Gunn and Peterson, 1991; Peterson et al., 1993), we find the highest relative hazard of first onset $(\mathrm{OR}=2.3)$ in the age range $10-14$.

Perhaps the most important finding in this paper is that there is no consistent sex difference in either chronicity or acute recurrence of depression in the age range studied in the NCS. It is important to recognize that any remaining sex difference in recall bias could distort this result. For example, it is possible that women actually have higher recurrence risks than men but that men are less likely than women to report the occurrence of a prior history of depression in the absence of a recent episode. A prospective research design is needed to evaluate this possibility. However, if we accept the data reported here on face value, we must conclude that the major determinant of the observed sex difference in 12-month depression is the greater risk of first onset among women compared to men. This difference begins early in lifc and persists through the mid-50s in the NCS, a pattern which is generally consistent with the ECA study (Burke et al., 1990). This finding suggests that our understand- 
ing of the sex difference in depression hinges largely on understanding why women are more likely than men to become depressed initially and why this sex difference is confined to a particular part of the life cycle. Once the first episode has occurred, neither chronicity nor acute cpisode recurrence plays an important part in determining the higher rate of active depression among women than men in the 15-54 year age range.

It is beyond the scope of this paper to evaluate the implications of these results for current theories about sex differences in depression. It is clear, though, that serious consideration of these results could lead to fundamental rethinking of some of these theories. For example, our results point to a difficulty with currently popular sex role theories of depression which argue that adult sex role stresses are important determinants of sex differences in depression (e.g., Barnett and Baruch, 1987; Gove and Geerken, 1977; Wilhelm and Parker, 1989). This is an inadequate explanation because sex differences in onset risk first emerge among early adolescents, prior to full adult sex role differentiation. Recognition of this discrepancy between the theory and the facts could lead to fruitful revision. For example, if adult sex role stresses have important direct effects on sex differences in depression, this is almost certainly more pronounced for adult-onset depression, which means that future research on the effects of adult sex role stresses should distinguish early-onset and later-onset disorders. Furthermore, an attempt should be made to investigate the possibility of selection processes whereby women with adolescent-onset depressions are differentially selected into adult sex roles which are known to be associatcd with high rates of chronic depression (e.g., single mothers).

\section{Acknowledgements}

The National Comorbidity Survey (NCS) is a collaborative epidemiologic investigation of the prevalence, causes, and consequences of psychiatric morbidity and comorbidity in the United States supported by the U.S. Alcohol, Drug Abuse, and Mental Health Administration (Grant 5 R01 MH46376) with supplemental support from the W.T. Grant Foundation (Grant 90135190),
Ronald C. Kessler, Principal Investigator. Preparation of this report was also supported by a Research Scientist Development Award to the first author (Grant $1 \mathrm{~K} 01 \mathrm{MH} 00507$ ). Collaborating NCS sites and investigators are: The Addiction Research Foundation (Robin Room), Duke University Medical Center (Dan Blazer, Marvin Swartz); Johns Hopkins University (James Anthony, William Eaton, Philip Leaf), the Max Planck Institute of Psychiatry (Hans-Ulrich Wittchen), the Medical College of Virginia (Kenneth Kendler), the University of Michigan (Lloyd Johnston, Ronald Kessler), the National Institute of Mental Health (Darrell Kirsch, Darrel Regier), New York University (Patrick Shrout), SUNY Stony Brook (Evelyn Bromet), The University of Toronto (R. Jay Turner), Washington University School of Medicine (Linda Cottler). A complete list of NCS publications can be obtained from the NCS Study Coordinator, Room 1006, Institute for Social Research, the University of Michigan, Box 1248, Ann Arbor, MI 48106-1248.

We would like to thank Evelyn Bromet and William Eaton for helpful comments and Rosetta Myers, Bruce Glasgow, and Sheri Levy for editorial assistance.

\section{References}

Allgulander, C. (1989) Psychoactive drug use in a general population sample, Sweden: correlates with perceived health, psychiatric diagnoses, and mortality in an automated record-linkage study. Am. J. Public Health 79, 1006-1010.

Allison, P.D. (1984) Event History Analysis. Sage: Beverly Hills.

Amenson, C.S. and Lewinsohn, P.M. (1981) An investigation into the observed sex difference in prevalence of unipolar depression. J. Abnorm. Psychol. 90, 1-13.

American Psychiatric Association. (1987) Diagnostic and Statistical Manual of Mental Disorders, 3rd Edn., Revised. Washington, DC: American Psychiatric Association.

Aneshensel, C. (1985) The natural history of depressive symptoms. Res. Commun. Mental Health 5, 45-75.

Anthony, J.C., Folstein, M., Romanoski, A.J., VonKorff, M.R., Nestadt, G.R., Chahal, R., Merchant, A., Brown, C.H., Shapiro, S., Kramer, M. and Gruenberg, E.M. (1985) Comparison of the lay Diagnostic Interview Schedule and a standardized psychiatric diagnosis. Experience in Eastern Baltimore. Arch. Gen. Psychiatry 42, 667-675.

Barneı, R.C. and Baruch, G.K. (1987) Social roles, gender and psychological distress. In: R.C. Barnett, L. Biener and 
G.K. Baruch (Eds.), Gender and Stress. The Free Press, New York, NY, pp. 122-143.

Bebbington, P.E. (1988) The social epidemiology of clinical depression. In: A.S. Henderson and G.D. Burrows (Eds.), Handbook of Social Psychiatry. Elsevier, Amsterdam, pp. 87-102.

Bebbington, P.E., Hurry, J., Tennant, C. and Wing, J.K. (1981) The epidemiology of mental disorders in Camberwell. Psychol. Med. 11, 561-579.

Bland, R.C., Newman, S.C. and Orn, H. (1988a) Period prevalence of psychiatric disorders in Edmonton. Acta Psychiatr. Scand. 77, 33-42.

Bland, R.C., Orn, H. and Newman, S.C. (1988b) Lifetime prevalence of psychiatric disorders in Edmonton. Acta Psychiatr. Scand. 77 (Suppl. 338), 24-32.

Boyd, J.H. and Weissman, M.M. (1981) Epidemiology of affective disorders. A reexamination and future directions. Arch. Gen. Psychiatry 38, 1039-1046.

Bradburn, N., Sudman, S. and Associates. (1979) Improving Interview Method and Questionnaire Design: Response Effects to Threatening Questions in Survey Research. Josse-Bass, San Francisco, CA.

Brooks-Gunn, J. and Petersen A.C. (1991) Studying the emergence of depression and depressive symptoms during adolescence. J. Youth Adolesc. 20, 115-119.

Burke, K.C., Burke, J.D., Regier, D.A. and Rae, D.A. (1990) Age of onset of selected mental disorders in five community populations. Arch. Gen. Psychiatry 47, 511-518.

Canino, G.J., Bird, H.R., Shrout, P.E., Rubio-Stipec, M., Bravo, M. et al. (1987) The prevalence of specific psychiatric disorders in Puerto Rice. Arch. Gen. Psychiatry, 14 727-735.

Cannell, C.F., Marquis, K.H. and Laurent, A. (1977) A summary of studies of interviewing methodology: 1959-1970. Vital Health Stat 2, Series 2, Number 69.

Cannell, C.F., Oksenberg, L. and Converse, J.M. (1979) Experiments in Interviewing Techniques. Survey Research Center, The University of Michigan: Ann Arbor, MI.

Chen, C., Wong, J., Lee, N., Chan-Ho, M., Lau, J.T. and Fung, M. (1993) The Shatin Community Mental Health Survey in Hong Kong: II. Major Findings. Arch. Gen. Psychiatry 50, 125-133

Cheng, T.A. (1989) Sex difference in the prevalence of minor psychiatric morbidity: a social epidemiological study in Taiwan. Acta Psychiatr. Scand 80, 395-407.

Cottler, L.B., Robins, L.N., Grant, B.F., Blaine, J., Towle, L.H., Wittchen, H. U., Sartortius, N. and Participants in the WHO/ADAMHA Field Trials (1991) The CIDI-core substance abuse and dependence questions: cross-cultural and nosological issues. Br. J. Psychiatry 159, 653-658.

Cross-National Collaborative Group (1992) The changing rate of major depression. Cross-national comparisons. J. Am. Med. Assoc. 268, 3098-3105.

Eaton, W.W., Anthony, J.C., Tepper, S. and Dryman, A. (1992) Psychopathology and attrition in the Epidemiologic Catchment Area Study. Am. J. Epidemiol. 135, 1051-1059.

Ernst, C. and Angst, J. (1992) The Zurich study XII. Sex difference in depression. Evidence from longitudinal epi- demiological data. Eur. Arch. Psychiatry Clin. Neurosci. $241,222-230$.

Farmer, A.E., Jenkins, P.L., Katz, R. and Ryder, L. (1991) Comparison of CATEGO-derived ICD-8 and DSM-III classifications using the composite international diagnostic interview in severely ill subjects. Br. J. Psychiatry 158, $177-182$.

Farmer, A.E., Katz, R., McGuffin, P. and Bebbington, P. (1987) A comparison between the Present State Examination and the Composite International Diagnostic Interview. Arch. Gen. Psychiatry 44, 1064-1068.

Gilbert, P. (1992) Depression: the Evolution of Powerlessness. Guildford Press, New York, NY.

Gotlib, I.H. and Hammen, C. (1992) Psychological aspects of depression: Toward a cognitive-interpersonal integration. John Wiley, Chichester, NY

Gove, W.R. and Geerken, M.R. (1977) The effect of children and employment on the mental health of married men and women. Soc. Forces 56, 66-76.

Hammen, C.L. (1982) Gender and depression. In: Al-Issa (Ed.), Gender and Psychopathology. Academic Press, New York, NY, pp. 133-152.

Helzer, J.E., Robins, L.N., McEvoy, L.T. and Spitznagel, E. (1985) A comparison of clinical and diagnostic interview schedule diagnoses. Arch. Gen. Psychiatry 42, 657-666.

Henson, R.M., Cannell, C.F., and Lawson, S.A. (1976) Effects of interviewer style on quality of reporting in a survey interview. J. Psychol, 93, 221-227.

Hosmer, D.W. and Lemeshow, S. (1989) Applied Logistic Regression. Wiley, New York, NY.

Hwu, H.G., Yeh, E.K. and Chang, L.Y. (1989) Prevalence of psychiatric disorders in Taiwan defined by the Chinese Diagnostic Interview Schedule. Acta Psychiatr. Scand. 79, 136-147.

Janca, A., Robins, L.N., Cottler, L.B. and Early, T.S. (1992) Clinical observation of CIDI assessments: An analysis of the CIDI field trials - Wave II at the St. Louis site. Br. J. Psychol. 160, 815-818.

Kalton, G. (1977) Practical methods for estimating survey sampling errors. Bull. Int. Stat. Inst. 47, 495-514.

Kendler, K.S., Neale, M.C., Kessler, R.C., Heath, A.C. and Eaves, L.J. (1992) A population-based twin study of major depression in women. The impact of varying definitions of illness. Arch. Gen. Psychiatry 49, 257-266.

Kessler, R.C., McGonagle, K.A., Zhao, S., Nelson, C.B., Hughes, M., Eshleman, S., Wittchen, H.-U. and Kendler, K.S. (submitted) Lifetime and active prevalence of DSMIII-R psychiatric disorders in the United States: Results from the National Comorbidity Survey.

Kish, L. and Frankel, M.R. (1970) Balanced repeated replications for standard errors. J. Am. Stat. Assoc. 65, 10711094.

Koch, G.G. and Lemeshow, S. (1972) An application of multivariate analysis to complex sample survey data. J. Am. Stat. Assoc. 67, 780-782.

Lee, C.K., Han, J.H. and Choi, J.O. (1987) The epidemiological study of mental disorders in Korea (IX): Alcoholism, anxiety and depression. Seoul J. Psychiatry, 12, 183-191. 
Lee, E. and Desu, M. (1972) A computer program for comparing $\mathrm{k}$ samples with right-censored data. Computer Programs in Biomedicine, \#2, 315-321.

Leitmeyer, P. (Ed.). (1990) Zur Symptomerfassung mit dem standarisierten Interview CIDI-C in der Allgemeinpraxis, Inauguraldissertation zur Erlangung des medizinischen Doktorgrades fur Klinische Medizin. Universitat Mannheim, Mannheim, Germany.

Lepkowski, J.M., Landis, J.R., Parsons, P.E. and Stehouwer, S.A. (Eds.). (1988) Statistical methodologies for analyzing a complex sample survey. National Medical Care Utilization and Expenditure Survey. Series A, Methodological Report No. 4 DHHS Pub. No. 88-20004. Public Health Service. U.S. Government Printing Office, Washington, DC.

Merikangas, K., Wicki, W. and Angst, J. (1993) Heterogeneity of depression: Classification of depressive subtypes by longitudinal course. Br. J. Psychiatry, in press.

Nolen-Hoeksema, S. (1987) Sex differences in unipolar depression: Evidence and theory. Psychol. Bull. 101, 259-282.

Petersen A.C., Compas B., Brooks-Gunn, J., Stemmler, M., Ey, S. and Grant, K. (1993) Depression in adolescence. Am. Psychol., in press.

Regier, D.A., Narrow, W.E., Rae, D.S. and Locke, B.Z. The stability of mental disorder prevalence--data from the NIMH ECA program. Presented at the Annual Meeting of the American Psychiatric Association, New Orleans, LA, May, 1991.

Robins, L.N., Helzer, J.E., Croughan, J.L. and Ratcliff, K.S. (1981) National Institute of Mental Health diagnostic interview schedule: Its history, characteristics and validity. Arch. Gen. Psychiatry 38, 381-389.

Robins, L.N., Wing, J., Wittchen, H.-U., Helzer, J.E. (1988) The Composite International Diagnostic Interview: An epidemiologic instrument suitable for use in conjunction with different diagnostic systems and in different cultures. Arch. Gen. Psychiatry 45, 1069-1077.

SAS Institute (1988) SAS 6.03. SAS Institute: Cary, NC.

Sargeant, K., Bruce, M.L., Floriol, P. and Weissman, M.M. (1990) Factors associated with one year outcome of major depression in the community. Arch. Gen. Psychiatry 47, 519-526.

Semler, G. (Ed.). (1989) Reliabilitat und Validitat des Composite International Diagnostic Interview. Inaugural-Dissertation zur Erlangung des akademischen Grades eines Doktors der Philosophie. Universitat Mannheim, Mannlieinl, Gernilany.

Semler, G., Von Cranach, M. and Wittchen, H.-U. (Eds.). (1987) Comparison Between the Composite International Diagnostic Interview and the Present State Examination Report to the WHO/ADAMHA Task Force on Instrument Development.

Simon, G.E. and VonKorff, M. (1992) Reevaluation of secular trends in depression rates. Am. J. Epidemiol. 135, 14111422 .

Spengler, P. and Wittchen, H.-U. (1989) Procedural validity of standardized symptom questions for the assessment of psychotic symptoms: A comparison of the CIDI with two clinical methods. Compr. Psychiatry 29, 309-322.

Sudman, S. and Bradburn, N. (1974) Response Effects in Surveys: A Review and Synthesis. Aldine, Chicago, IL.

Turner, C.F. and Martin, E. (1984) Surveying Subjective Phenomena, Vol. I. Russell Sage, New York, NY.

U.S. Department of Health and Human Services. (1992) National Health Interview Survey, 1989 (Computer file). National Center for Health Statistics, Hyattsville, MD

University of Michigan (1981) OSIRIS VII. Institute for Social Research, The University of Michigan, Ann Arbor, MI.

Wacker, H.R., Battegay, R., Mullejans, R. and Schlosser, C. (1990) Using the CIDI-C in the general population. In: C.N. Stefanis, A.D. Rabavilas and C.R. Soldatos (Eds.), Psychiatry: a World Perspective. Elsevier, Amsterdam, pp. $138-143$.

Weissman, M.M., Bland, K., Joyce, P.R., Newman, S., Wells, J.E., and Wittchen, H-U (1993) Sex differences in rates of depression: cross-national perspectives.

Weissman, M.M., Bruce, M.L., Leaf, P.J., Florio, L.P. and Holzer, C., III (1991) Affective disorders. In: L.N. Robins and D.A. Regier (Eds.), Psychiatric Disorders in America. Free Press, New York, NY.

Weissman, M.M. and Klerman, G.L. (1992) Depression: Current understanding and changing trends. Annu. Kev. Public Health 13, 319-339.

Weissman, M.M. and Klerman. J.K. (1985) Gender and depression. Trends Neurosci. 8, 416-420.

Weissman, M.M and Klerman, J.K. (1977) Sex differences and the epidcmiology of depression. Arch. Gcn. Psychiatry 34, 98-111.

Weissman, M.M., Leaf, P.J., Holzer, C.E., III, Myers, J.K. and Tischler, G.L. (1984) The epidemiology of depression. An update on sex differences in rates. J. Affect. Disord. 7, 179-188.

Weissman, M.M. and Myers, J.K. (1978) Affective disorders in a U.S. urban community. Arch. Gen. Psychiatry 35, 13041311.

Wells, J.E., Bushnell, J.A., Hornblow, A.R., Joyce, P.R., Oakley-Browne, M.A. (1989) Christchurch Psychiatric Epidemiology Study, Part I: Methodology and lifetime prevalence for specific psychiatric disorders. Aust. NZ J. Psychiatry 2.3, 315-326.

Wilhelm, K. and Parker, G. (1989) Is sex necessarily a risk factor to depression? Psychol. Med. 19, 401-413.

Wittchen, H.-U., Burke, J.D., Semler, G. and Pfister, H. (1989) Recall and dating of psychiatric symptoms: Test-retest reliability of time-related symptom questions in a standardized psychiatric interview. Arch. Gen. Psychiatry $46,437-443$.

Wittchen, H.-U., Fssau, C..A., von Zerssen, D., Krieg, I.C., and Zaudig, M. (1992) Lifetime and six-month prevalence of mental disorders in the Munich follow-up study. Eur. Arch. Psychiatry Clin. Neurosci. 241, 247-258.

Wittchen, H.-U., Robins, L.N., Cottler, L.B., Sartorius, N., Burke, J.D., Regier, D.A. and Participants in the Multi- 
centere WHO/ADAMHA Field Trials. (1991) Cross-cultural feasibility, reliability and sources of variance in the Composite International Diagnostic Interview (CIDI). Br. J. Psychiatry 159, 645-653.

Woodruff, R.S. and Causey, B.D. (1976) Computerized method for approximating the variance of a complicated estimate. I. Am. Stat. Assoc. 71, 315- 321.

World Health Organization (1990a) Composite International Diagnostic Interview, (CIDI, Version 1.0). World Health Organization: Geneva.
World Health Organization. (1990b) International Classification of Diseases - 10 Classification of Mental and Behavioral Disorders: Diagnostic Criteria for Research. World Health Organization: Geneva.

Young, M.A., Fogg, L.F., Scheftner, W.A., Keller, M.B. and Fawcett, J.A. (1990) Sex differences in the lifetime prevalence of depression. I. Affect. Disord. 18, 187-192. 